\title{
Concepciones sobre sexualidad en adolescentes y padres, a partir de psicodramas*
}

\author{
Adolescents and Parents Conceptions about Sexuality based on \\ Psychodrama
}

Concepções de sexualidade em adolescentes e pais, a partir de psicodramas

Recibido el 25 de octubre de 2016. Aceptado el 5 de julio de 2017

Héctor Alexander Afanador Castañeda**

Colombia

\section{Resumen}

Objetivos: identificar las concepciones de

Para citar este artículo:

Afanador Castañeda, Héctor

Alexander (diciembre, 2017).

Concepciones sobre sexualidad

en adolescentes y padres, a partir de psicodramas. Ánfora,

24(43), 87-108. Universidad

Autónoma de Manizales. ISSN

0121-6538. adolescentes (mujeres y hombres) y sus padres sobre la práctica sexual, para establecer relación entre las concepciones de los padres y madres con la de sus hijos e hijas y determinar si los conceptos de los participantes responden a un proceso evolutivo, según las demandas sociales actuales. Metodología: se empleó el psicodrama como técnica para la formulación del texto escrito. Se hizo análisis de los textos escritos para la reconstrucción de significados de los segmentos que permitieron la descripción de datos en cada una de las subcategorías. La población objeto de estudio se

\footnotetext{
* Esta investigación hace referencia a las actividades de introducción de nuevos puntos de vista de la fase de implementación del Proyecto Pedagógico de Aula "Construyo mi sexualidad desde mi adolescencia", durante el 2013. Este proyecto se desarrolla en el ciclo educativo cuatro (grados octavos y novenos) de la Institución Educativa Distrital Charry de Bogotá (Colombia). El proyecto históricamente nace hace cinco años, el cual fue radicado en la Red de profesores sobre Género de la Secretaría de Educación Distrital de Bogotá, en el año 2014 y continúa a la fecha. Los datos recopilados aquí corresponden a noviembre de 2015.

** Magíster en Didáctica de las Ciencias. Licenciado en Biología. Docente adscrito a la Secretaría de Educación Distrital de Bogotá (Colombia), e Investigador del grupo Conocimiento Profesional del Profesor de Ciencias, de la Universidad Pedagógica Nacional. Correo electrónico: haacster@gmail.com.
} 
conformó con estudiantes de colegio de Bogotá, Colombia, de 14 a 17 años (hombres y mujeres) con sus respectivos padres. Resultados: los diálogos entre padres e hijos revelaron rasgos tradicionales (el acto sexual solo es para adultos y en el matrimonio, los hombres solo buscan sexo, el sexo prematrimonial es pecado, etc.), en los que prevalece el sexismo benevolente; es decir, las concepciones en ambos géneros de adolescentes responden a estereotipos de roles sociales establecidos a partir de diferencias sexuales como hombre ideal (se responsabiliza de la mujer) y mujer juiciosa (cuida su imagen) transmitidos por los padres. Conclusiones: los participantes manifestaron un periodo de transición entre el conservacionismo social (moralizador y autoritarismo) y el evolucionismo social que le dificulta aceptar que los adolescentes son sujetos sexuados de derecho que requieren, más que un adoctrinamiento, formación sexual crítica y reflexiva que les permita enfrentar una sociedad cambiante.

Palabras Clave: Sexualidad; Adolescentes; Psicodrama; Padres de familia.

\section{Abstract}

Objective: to identify the adolescents' and their parents' conceptions (men and women) about sexual practices in order to establish a relationship between the conceptions of both parents and their children, and to determine whether the concepts of these participants respond to an evolutionary process, according to the current social demands. Methodology: psychodrama was used as a technique for the formulation of the written text. Analysis of the written texts was made to reconstruct the meanings of segments that allowed the description of data in each of the subcategories. The study population was made up of college students from Bogotá, Colombia, between 14 and 17 years old (men and women) with their respective parents. Results: the dialogues between the parents and the children revealed traditional features (a sexual act is only for adults when married, men only seek sex, premarital sex is a sin, etc.), in which benevolent sexism prevails. That is to say, conceptions in both genders of adolescents respond to stereotypes of social roles which are established on the basis of sexual differences, such as the ideal man (responsible for the woman) and the responsible woman (cares for her image) transmitted by parents. Conclusions: participants exhibited a period of transition between social conservationism (moralizing and authoritarianism), and social evolutionism, that makes it difficult for them to accept that adolescents are sexed subjects of law that require, rather than indoctrination, critical and reflective sexual training which allows them to face a changing society.

Key words: Sexuality; Adolescents; Psychodrama; Parents. 


\section{Resumo}

Objetivo: identificar as concepções de adolescentes (mulheres e homens) e seus pais sobre a prática sexual, para estabelecer relação entre as concepções dos pais com as concepções de seus filhos e determinar se os conceitos dos participantes respondem a um processo evolutivo, de acordo com as demandas sociais atuais. Metodologia: foi utilizado o psicodrama como técnica para a formulação do texto escrito. Foi feita uma análise dos textos escritos para a reconstrução dos significados dos segmentos que permitiram a descrição de dados em cada uma das subcategorias. A população objeto de estudo foi formada com estudantes de colégio em Bogotá, Colômbia, de 14 a 17 anos (homens e mulheres) com seus respectivos pais. Resultádos: os diálogos entre pais e filhos revelaram características tradicionais (o sexo é apenas para adultos casados, os homens só procuram sexo, o sexo antes do casamento é um pecado, etc.), nas que prevalece o sexismo benevolente, ou seja, as concepções em ambos gêneros de adolescentes respondem aos estereótipos sociais estabelecidos a partir de diferenças sexuais como homem ideal (quem é responsável da mulher) e mulher calma (quem cuida de sua imagem) transmitidos pelos pais. Conclusões: os participantes expressaram um período de transição entre o conservadorismo social (moralista e autoritário) e o evolucionismo social para o que é difícil aceitar que os adolescentes são sujeitos sexuados de direito que precisam mais que uma doutrinação, uma formação sexual crítica e reflexiva que lhes permita enfrentar uma sociedade em constante mutação

Palavras-chave: Sexualidade; Adolescentes; Psicodrama; Pais de família. 


\section{Introducción}

Es de suma importancia abordar la educación sexual en adolescentes ${ }^{1}$, bien sea desde la interdisciplinariedad o la biología, con el propósito de generar impacto social. Las dificultades del sistema educativo, sin embargo, se abordan desde los planteamientos políticos que ignoran la moderna investigación sexual (Ruby, s. f.). También se plantea desde contenidos transmisionistas o informativos unidireccionales que responden a aspectos biológicos (transmisión de infecciones de transmisión sexual (ITS) y prevención del embarazo temprano), hasta una enseñanza descontextualizada que se inscribe en los modelos sociales autoritarios.

Lo anterior, conlleva sobrecargas de tabúes culturales sobre la educación sexual y la nula participación y opinión del adolescente (aprendiente) en los espacios formativos y educativos. Según Silva (2011), todo esto dificultaría emprender un abordaje en torno a las problemáticas sexuales. Al respecto, Heilborn (1999), recalca que es importante que en el aula haya un discurso escolar sobre la sexualidad y reconoce que las construcciones sociales deben contener tanto conocimientos culturales como científicos; pero existen diferencias en la formación de la sexualidad entre los adolescentes según el género, en las que sus opiniones y diálogos responden a reglas tradicionales o culturales (Afanador, 2014).

Agudelo (2004) insiste que la sexualidad humana es parte fundamental de la sociedad y que ésta es interdependiente a la moral y a los cambios sociales; existe una escala de valores y vivencia que no tiene la significancia, es decir, no tienen la misma tradicionalidad. Esto, interpretado desde los planteamiento de Foucault (2007), los sujetos (estudiantes y padres) en los dominios de las relaciones de poder (macro-sociales y micro-sociales), que comportan sus relaciones diferenciales entre fuerza, exhiben asimetrías; tales asimetrías están dadas por fuerzas internas (las normas de comportamiento social sobre la sexualidad y las tradiciones culturales que transmite la familia) que intentan conducir a la otra (representación social, y el mismo deseo sexual, del adolescente).

En tal sentido, los discursos en torno al sexo se han planteado como mecanismos de fuerza y control (no de dominación), pues arguyen poder (son los padres los responsables del bienestar de los estudiantes) y conocimiento (el cúmulo de experiencias socio-históricas que tienen los adultos), que envuelven

\footnotetext{
1. Se asume que la adolescencia es un periodo de transición entre la niñez y la edad adulta, en la que sujetosadolescentes afrontan grandes cambios -definición de su identidad y preparación a la ciudadanía- y desafíos evolutivos -independencia en el contexto familiar y reconocimiento social- (Musitu y Cava 2003), siendo necesarios para la adaptación en realidades cambiantes y su desarrollo en un contexto particular y situacional. En este sentido, se distancia de la representación cultural conservacionista (individuos opositores a la autoridad que deben ser adoctrinados en normas y valores por el adulto).
} 
elementos tácticos (las tradiciones sociales son modos prácticos de actuar y pensar) configurando así, el campo de las relaciones de fuerza (entre padres o madres e hijos o hijas). Por ende, los diálogos son elaborados y cuidadosamente cifrados bajo estrictas condiciones de control "el sexo es un secreto" que incluyen o involucran altos grados de valores morales y principios éticos que rigen la conducta de forma tradicional o conservadora (Altmann y Martins, 2009).

Entonces la sexualidad está influenciada por la cultura; las normas sociales, religiosas, políticas, jurídicas etc., condicionan los comportamientos de los sujetos (Berger, et al, 2008) que incluyen demandas explícitas y advertencias del cómo se debe experimentar a través de las interacciones sociales (Musitu, 2000). Las interacciones, pueden estar acompañadas de representaciones o esquemas que dependen de los valores y creencias compartidas por el grupo social (puntos de vista en común expresada durante las interacciones sociales que dependen de la percepción emocional y las respuestas de los sujetos a las demandas de su grupo social) como elementos decisivos para relacionarse con el mundo (Berger, et al., 2008) y requisitos para construir una moral legitimadora (Agudelo, 2004).

Se puede interpretar que estas ideologías, portan una presunta condición de moralidad, e inducen a reconocer la autoridad (a través de prototipos categorizados) convirtiéndose este proceso de formación en adoctrinamiento o condicionantes fijos que alejan de la realidad contextualizada (no existe autonomía ni poder de decisión). Así, la moralidad surge como un mecanismo de regulación socio cultural, con poca participación de las personas; por eso es una moral impositiva (Goergen, 2005), con la intención de preservar los valores establecidos, los cuales generan seguridad y mantienen la tradición (Agudelo, 2004).

Aunque exista una divergencia entre Estado e Iglesia, ambos pretenden legitimar sus prácticas institucionales con efectos de verdad, solidificándose como prácticas socialmente aceptadas (Cárdenas, Contreras y Navarro, 2011). A diferencia de los valores que se ejercen desde el arte, la ciencia, la política, entre otras, la moral en la sexualidad responde a un sistema de reglas o normas imperativas, resguardadas (ocultas y acríticas) o respaldadas desde lo socio cultural. Según Durkheim (1998), responde a un conjunto de creencias o dogmas por influencia y persistencia de hechos a lo largo de la historia, refugiado en la religión o por asimetría generacional, ya que la experiencia social acumulativa brinda la base racional para la toma de decisiones, legitimando una lógica de dominio (Narodowski, 2011); así, la legitimación (el reconocimiento, cumplimiento y sanción de normas) responde a la justificación moral en la sociedad, que a su vez, es mecanismo competitivo que tiene papel de regulador (Foucault, 2007).

Lo anterior, invita a mirar el contexto particular y situacional de la sexualidad como un asunto relevante para problematizar: ¿qué concepciones expresan 
los adolescentes en cuanto a la práctica sexual?, ¿existe relación entre las concepciones sobre la práctica sexual de adolescentes con los de sus padres y/o madres?, ¿las concepciones sobre la práctica sexual de los participantes responden a las demandas sociales actuales de diálogo abierto, la autonomía, la libertad y el respeto a la intimidad entre padres y madres e hijos e hijas, o se mantiene en el autoritarismo, el ocultismo, el pecado y la inmoralidad, que se desprende del mismo acto sexual? En ese sentido, se asume que los procesos participativos de adolescentes deben darse para que existan cambios o evoluciones de conductas y comportamientos inadecuados y tradicionales en ellos (Afanador, 2014), así mismo evidencias para responder dichas preguntas.

Esta polémica socio-cultural, implica afirmar la coexistencia de lo tradicional y el cambio a lo tradicional en la sociedad de hoy, puesto que la dinámica de coexistencia entre estos dos fenómenos (es abierta y descentralizada gracias a las interacciones entre sujetos) es legitimada si los sujetos construyen su identidad, bien sea desde procesos de aceptación e incorporación o desde la adaptación, supervivencia, resistencia y crítica a los modelos vigentes (Bonder 2008), que repercuten en los mismos escenarios socio-culturales, y/o, del rompimiento de la asimetría posfigurativa, donde prevalece el intercambio generacional (Narodowski, 2011).

Entonces, se justifica la implementación y realización de este estudio investigativo, a partir de los siguientes objetivos: identificar las concepciones de ambos géneros adolescentes (mujeres y hombres) y de sus respectivos padres sobre la práctica sexual, establecer relación entre las concepciones sobre la sexualidad de los padres y/o madres con la de sus hijos (mujeres y hombres), y determinar si las concepciones sobre la práctica sexual de los participantes responden a un proceso evolutivo acorde a las demandas sociales actuales.

\section{Metodología}

Este diseño metodológico cualitativo desde el estudio de caso pretendió obtener descripciones y realizó interpretaciones sobre las concepciones de la práctica sexual. La técnica empleada de intervención fueron los psicodramas ${ }^{2}$ (comprendida en su más extensa definición como secuencia de eventos

\footnotetext{
2. Al tener en cuenta que la sexualidad es un producto de negociación y acción humana (Weeks, 1998), fue importante que la técnica de psicodramas incorporará elementos de la teoría Vygotskyana - las zonas próximas son necesarias para la adquisición de verdaderos aprendizajes, puesto que negocian los saberes previos con los nuevos saberes (Cole, 1984) -, dentro de la estrategia didáctica ya que facilito recoger los datos a partir de las negociaciones entre los padres y madres con sus hijos e hijas adolescentes sobre la sexualidad dentro de un contexto particular.
} 
simulados que propician la espontaneidad del sujeto para obtener de este mismo, multiplicidad de diversas respuestas que posean sentido inventor, innovador, crítico, reflexivo, etc.).

Los psicodramas fueron relevantes porque colocan en juego situaciones sociales "simuladas" en desarrollo, permitiendo a los sujetos (hijos y padres) representarse a sí mismos realidades hipotéticas o casos vivenciales que pueden vivir o experimentar (Cohen y Manion 1990), que luego del actuar (re-construcción de la representación mental sobre los hechos narrados) les permite hablar de ello en función de las representaciones sociales. Sin embargo, para obtener este diálogo de los sujetos sobre la situación simulada, según Cornejo (1992), debe cumplirse el vínculo entre el reflejo de su conducta (yo) y la conducta del otro (tú, en este caso narrado); es decir, la conformación de la unidad funcional de conducta permite a los sujetos interaccionar con otros frente a la situación planteada desde sus creencias, concepciones y percepciones.

Por ende, el uso de los psicodramas en esta investigación apuntó a obtener datos relevantes de concepciones sobre sexualidad de la población intervenida, a partir de textos escritos que surgían de las interacciones entre los actores de la comunidad escolar, estudiante-estudiante, padre-estudiante, y la producción de textos (crítico-reflexivos) sobre las mismas situaciones hipotéticas.

Esta producción escrita fue interpretada desde el planteamiento de reconstrucción de significados, en el que los segmentos textuales, o unidades de contenido, permiten hallar subcategorías que dejan ver una concepción completa del estudiante y padre o madre, sobre la sexualidad (Cucatto, 2013). Entonces, la agrupación de modelos verbales como lo recomiendan Coad y Yourdon (1990) y Chen (1976), facilitó el análisis del contenido en las subcategorías (acto sexual, conducta de género y métodos anticonceptivos).

La población participante corresponde al grado noveno (con sus respectivos padres) de colegio oficial entre las edades de 14 a 17 años (según rango de Musitu y Cava 2003, adolescencia media), perteneciente a la localidad de Engativá de Bogotá (Colombia) con estratos socio-económicos 1 y 2. Los datos preliminares de participación en el instrumento empleado (libro) como psicodrama a partir de 34 casos, indican que solo 9 hombres adolescentes y 25 mujeres adolescentes fueron participantes activos $(57 \%)$ con el respectivo acompañamiento y socialización de los padres (solo se registra 1 caso de no acompañamiento en los psicodramas). Además, resalta la alta participación de las mamás y la baja participación de los papás, en la mediación de saberes sobre la dimensión de la sexualidad. Estos datos determinan que el análisis responde a un contexto situacional - muy particular donde existió mayor participación activa en la mujer (adolescente y madres).

Para las descripciones de los resultados se realiza a partir de grupos según: el género y la coincidencia de las unidades de análisis. A continuación, los grupos: 
Grupo 1: adolescentes hombres a favor del acto sexual. Grupo 2: adolescentes hombres en contra del acto sexual. Grupo 3: adolescentes mujeres en contra del acto sexual. Grupo 4: adolescentes mujeres a favor del acto sexual. Grupo 5: ambos padres de los adolescentes (viven con padre y madre). Grupo 6: mamás de los adolescentes (solo viven con su progenitora). Grupo 7: ambos padres de las adolescentes (viven con padre y madre). Grupo 8: mamás de las adolescentes (solo viven con su progenitora). Grupo 9: papás de las adolescentes (solo viven con su progenitor).

\section{Resultados}

En esta sección se presentan las síntesis de las descripciones seguida de los datos o unidades de análisis dentro de cuatro tablas o cuadros, agrupados en tres subcategorías (acto sexual, conducta de género y métodos anticonceptivos) a partir de los grupos ya mencionados (ver tablas). Luego de esto, se realiza la debida discusión teórica sobre las descripciones de forma integral para comprensión del problema en el estudio de caso (práctica sexual) ${ }^{3}$. A continuación, se precede con lo dispuesto:

\section{Concepciones sobre el acto sexual}

El acto sexual ${ }^{4}$ es comprendido como acción o manifestación de placer y deseo como el coito y la autosatisfacción, que se percibe a partir de las zonas sexuales y erógenas, así mismo de los lazos afectivos y de compromiso social que de éste se desprende. En ese sentido, los hallazgos hacen referencia al agrupamiento de las concepciones de aceptación del acto sexual en adolescentes en cada uno de los grupos, se indica que existen diferencias marcadas entre los mismos grupos de adolescentes y entre los mismos grupos de padres (ver tabla 1 y tabla 2).

\footnotetext{
3. Las prácticas sexuales sonel resultado de "prácticas sociales que dan significado a las actividades humanas, de definiciones y autodefiniciones, de luchas entre quienes tienen poder para definir y reglamentar contra quienes se resisten" (Weeks, 1998, p. 30).

4. El acto sexual adquiere relevancia porque está inmersa dentro de la práctica sexual.
} 
Tabla 1. Concepciones de adolescentes sobre el acto sexual

\begin{tabular}{cc} 
Grupos & Descripciones \\
\hline Uno & $\begin{array}{c}\text { Es una acción común dentro de los adolescentes y necesario } \\
\text { para la manifestación de sentimientos que se realiza dentro } \\
\text { del noviazgo, "este acto se realiza después de cierto periodo a lo } \\
\text { que ellos llaman "conocer a la otra persona" siendo relevante para } \\
\text { reafirmar el compromiso verdadero. }\end{array}$ \\
\hline Dos & $\begin{array}{c}\text { Posición radical, no a la práctica sexual entre adolescentes. } \\
\text { "El sexo es una exposición" ("con o sin uso de preservativo trae } \\
\text { graves consecuencias, bien sea físicas, alguna ETS, psicológica } \\
\text { depresión o frustración") y "la formación de los y las adolescentes } \\
\text { debe contribuir a la toma de decisiones. }\end{array}$ \\
\hline Tres & $\begin{array}{c}\text { Rechazo al acto sexual. "No debe presentarse en esta etapa", } \\
\text { "las condiciones para acceder al sexo, es después de terminar el } \\
\text { colegio" y "preferible en el matrimonio". }\end{array}$ \\
\hline Cuatro & Son "actos normales (o comunes) y se dan entre adolescentes". \\
\hline
\end{tabular}

Fuente: elaboración propia

La tabla 1, muestra diferencias entre los grupos de adolescentes hombres donde el grupo 1, se encuentra a favor considerándola una actividad normal que tienen los hombres en su vida adolescente, mientras que el grupo 2 lo consideran un acto de riesgo. De igual modo ocurre en los grupos de adolescentes mujeres, para el grupo 3 se considera que el acto sexual solo pertenece a la vida adulta dentro del matrimonio; esta concepción es muy diferente a la del grupo 4, en el que se consideró que la sexualidad es una actividad normal entre ellas.

Tabla 2. Concepciones de padres sobre el acto sexual.

\begin{tabular}{cc} 
Grupos & Descripciones \\
\hline Cinco & $\begin{array}{c}\text { los adolescentes - hombres "pueden tener sexo, siempre y cuan- } \\
\text { do, sean responsables", es decir, que "no dejen a una jovencita } \\
\text { embarazada". }\end{array}$ \\
\hline Seis & $\begin{array}{c}\text { los hijos adolescentes no deben tener sexo y enamorarse } \\
\text { ("eso hace que se desjuicien ya que solo se dedican a la novia o } \\
\text { a las novias"). Las mujeres son las responsables que sus hijos } \\
\text { tengan relaciones sexuales ("buscan, excitan y engañan a los } \\
\text { adolescentes"). }\end{array}$ \\
\hline Siete & $\begin{array}{c}\text { Las hijas no deben tener relaciones sexuales "por ser adoles- } \\
\text { centes, según ellos deben cuidar su cuerpo, mente y bienestar". }\end{array}$
\end{tabular}




\begin{tabular}{c}
\hline $\begin{array}{c}\text { No rotundo a la práctica sexual, ("el sexo solo se realiza cuando } \\
\text { se casa -matrimonio o unión libre", además "el sexo es pecado } \\
\text { fuera del matrimonio"). }\end{array}$ \\
\hline Nueve \\
$\begin{array}{c}\text { Aceptan que su hija tenga relaciones sexuales, pero con la } \\
\text { condición que planifique ("toda mujer debe planificar") }\end{array}$ \\
\hline
\end{tabular}

Fuente: elaboración propia

Para el caso de los grupos padres (tabla 2), en el grupo 5 se aprueba que los hombres tengan relaciones sexuales, siempre y cuando no haya consecuencias a posteriori (concepción relacionada con la del grupo 1), a diferencia de la concepción del grupo 6 que está en contra del acto sexual en adolescentes responsabilizando a la mujer como inductora. Estas concepciones son diferentes cuando se refieren a la adolescente mujer; nótese que los grupos 7 y 8 el grupo se oponen a las relaciones sexuales de las adolescentes desde visiones biológicas y religiosas, similares a los de sus hijos e hijas (grupo 2 y grupo 3). Mientras que la concepción del grupo 9, se aparta de la visión conservadora y comparte con la expresada por el grupo 4.

\section{Concepciones acerca de la conducta de género en la práctica sexual y el desarrollo sexual}

La conducta de género ${ }^{5}$ hace referencia a todas las acciones que desarrolla el y la adolescente como la de sus padres y madres, frente a situaciones que involucran la práctica sexual y su desarrollo en un contexto de juicios de valor, emociones, creencias, pensamientos y conocimientos. De tal modo que los datos de las concepciones de la subcategoría conducta de género en la práctica sexual y el desarrollo sexual, en gran medida son compartidas en los grupos (ver tabla 3 y tabla 4$)$.

5. Desde uno de los planteamientos de Scott, J. (1996) sobre género, se asume que esta subcategoría, se utiliza para designar las relaciones sociales entre sexos y denotar las construcciones culturales y la creación social de ideas sobre los roles apropiados para mujeres y hombres, siendo entonces, la forma de referirnos a los orígenes sociales de las identidades subjetivas de hombres y mujeres. 
Afanador Castañeda, Héctor Alexander (diciembre, 2017). Concepciones sobre sexualidad en adolescentes y padres, a partir de psicodramas. Ánfora, 24(43), 87-108. Universidad Autónoma de Manizales. ISSN 0121-6538.

Tabla 3. Concepciones de adolescentes sobre la conducta de género en el desarrollo sexual

Grupos

\begin{tabular}{|c|c|}
\hline Ginpos & \\
\hline Uno & $\begin{array}{l}\text { "Ser hombre es responder como hombre", otras características propias: } \\
\text { hombre cuidador y protector, también "hombre responsable, el cual } \\
\text { "toma decisiones y asume consecuencias", donde el sexo es parte funda- } \\
\text { mental de su experiencia como hombre dentro del noviazgo } \\
\text { "Mujer ideal", características: monogámica y carente de experiencia } \\
\text { sexual, "es quien se entrega al hombre para permanecer a su lado con la } \\
\text { intención de ser cuidada y protegida dentro del noviazgo". Y "mujer desea- } \\
\text { da" características: "tiene mayor atractivo físico", "responsables de que los } \\
\text { hombres las utilicen". }\end{array}$ \\
\hline Dos & $\begin{array}{c}\text { No hay diferencias de género. Consideran que ambos presentan } \\
\text { inmadurez en el desarrollo sexual, según ellos, "no tienen la suficiente } \\
\text { consciencia para responder por sus actos o por otra persona". }\end{array}$ \\
\hline \multirow[t]{2}{*}{ Tres } & $\begin{array}{c}\text { "Existen conductas machistas en ambos sexos", "son enseñadas por los } \\
\text { padres o adquiridos por cuestiones culturales que inciden en las relaciones } \\
\text { de noviazgo". Los hombres, "solo buscan aventuras sexuales (todos)" y } \\
\text { "quieren reclaman la virginidad de una mujer como trofeo" }\end{array}$ \\
\hline & $\begin{array}{l}\text { Las mujeres: "son inocentes", "románticas", "juiciosas", "con buenos senti- } \\
\text { mientos e inteligentes que deben cuidarse y no entregarse a los hombres". } \\
\text { Además, "cuando tiene una relación presenta a su novio o amigo con } \\
\text { sus padres o a la mamá, es por esto que la mayoría de los hombres no la } \\
\text { buscan". }\end{array}$ \\
\hline \multirow[t]{2}{*}{ Cuatro } & $\begin{array}{l}\text { Hombre "ideal o caballero, tiene muy poca experiencia en relaciones } \\
\text { sexuales y de sentimientos nobles", con el cual "se comparte pensamien- } \\
\text { tos, u hombre caballero que se caracteriza por adquirir su compromiso" y } \\
\text { responsabilidad al tener sexo". Y hombre "no ideal o machista o muje- } \\
\text { riego o perro" (alta experiencia en el sexo), "juega con los sentimientos de } \\
\text { la mujer", solo busca placer a partir de la apariencia física ("solo tiene } \\
\text { sexo con mujeres bonitas"), además es "morboso" " "vive insinuándose a } \\
\text { las mujeres con expresiones dulces o promesas falsas o busca un mínimo } \\
\text { motivo para acosar". }\end{array}$ \\
\hline & $\begin{array}{c}\text { Mujer "normal o reservada" cuando "cuida de su imagen y se respeta a } \\
\text { sí misma", por lo tanto, "el tener sexo se realiza en el noviazgo, siemprey } \\
\text { cuando, sea "con el hombre ideal bajo el principio de fidelidad y la madura- } \\
\text { ción de la relación". Y mujer "lanzada o regalada" se caracteriza: "siempre } \\
\text { está alrededor o busca a los hombres para tener experiencias sexuales" } \\
\text { y "son a las que los hombres vuelven trompo de poner" o "se ofrece a los } \\
\text { hombres en el sexo". }\end{array}$ \\
\hline
\end{tabular}

Fuente: elaboración propia 
Teniendo en cuenta la tabla 3, el grupo 1 se inclinó por la representación socio-cultural conservacionista del hombre y de la mujer dentro de la sexualidad (ideación e idealización), muy atado al rol de cada género. En cambio el grupo 2 mantiene su opinión de acto de riesgo que no puede ser asumida por personas adolescentes. Con respecto a los grupos femeninos (3 y 4 ), las concepciones responden al conservacionismo romántico y a patrones culturales de la monogamia de acuerdo con los datos del grupo 3 (hombres machistas o aventureros y mujeres educadas o valoradas); mientras que el grupo 4 enfatiza sobre el comportamiento para identificar que tanto hombres como mujeres tienen los mismos comportamientos (hombres perros y mujeres lanzadas u hombre ideal y mujer recatada).

Tabla 4. Concepciones de padres sobre la conducta de género en el desarrollo sexual

\begin{tabular}{cc} 
Grupos & Descripciones \\
\hline Cinco & $\begin{array}{c}\text { Visión incluyente, la juventud "presenta conductas o comportamientos } \\
\text { inmaduros e irresponsables ante las prácticas sexuales, quieren ser grandes } \\
\text { sin serlos". }\end{array}$ \\
\hline Seis & $\begin{array}{c}\text { La mujer "normal, la que no busca al hombre y está en su casa". Y mujer } \\
\text { "acosadora, la que está encima o pegada al...hombre y que no respeta la } \\
\text { casa de él". Según ellas, "son ellas las que buscan un embarazo". }\end{array}$ \\
\hline Siete & $\begin{array}{c}\text { El hombre clasificado en: sexual "solo piensa en sexo y se caracteriza por } \\
\text { cargar condones". Machista "ve a la mujer como objeto debido a que esta } \\
\text { condición la heredan de los padres". Y social "solo piensa en tener pareja y } \\
\text { deposita ciegamente, la confianza en la mujer sobre el uso de métodos de } \\
\text { planificación". } \\
\text { Los adolescentes sentimentales son aquellos que "desconocen los } \\
\text { riesgos del sexo en el noviazgo" }\end{array}$ \\
Ol hombre clasificado en: irresponsable "solo buscan sexo y si queda \\
embarazada se desaparecen". Machista "hereda el comportamiento del \\
papá con pocos valores hacia la mujer". Y Pecador "induce a las mujeres a \\
tener sexo antes del matrimonio". \\
Adolescentes pecadores "sexo por fuera del matrimonio".
\end{tabular}

Fuente: elaboración propia

Así mismo, puede indicarse en los grupos de los padres (tabla 4) que la responsabilidad es por igual en ambos géneros de adolescentes (grupos 5 y 9). Los grupos 6, 7 y 8 evidenciaron tipologías de género socio - cultural frente a 
la conducta de desarrollo sexual, en las cuales los adjetivos despectivos (mujer acosadora y hombre perro, hombre machista, hombre irresponsable, hombre pecador), están asociados a la conducta de riesgo y de la misma práctica sexual, de tal modo que sus análogos se suprimen (o son suprimidos) del deseo y el placer sexual. Cabe decir que existe una misma representación social entre los grupos 3 y 7 , y 4 y 8.

\section{Concepciones sobre los métodos anticonceptivos}

Los métodos anticonceptivos son medios (acto, dispositivo o medicamento) para impedir un embarazo viable o no deseado y para la protección ante una infección de transmisión sexual. A continuación, se presentan los resultados de concepciones en esta subcategoría.

Tabla 5. Concepciones de adolescentes sobre métodos anticonceptivos.

\begin{tabular}{cc} 
Grupos & Descripciones \\
\hline Uno & "En la práctica es fundamental el uso del condón", "todo hombre debe \\
cargary saber utilizar el preservativo (es quien porta y usa) para evitar el \\
embarazo en las mujeres". Y al estar expuesto al peligro sexual (ante mu- \\
jeres deseadas) su acción como hombre es la de "comunicar a sus padres y \\
buscar ayuda especializada ante embarazos y ETS".
\end{tabular}

Fuente: elaboración propia 
Según los datos de la tabla 5, se identificó en las concepciones de hombres y mujeres adolescentes que el grupo 1 y el grupo 2 (hombres) y grupo 4 (mujeres), son consecuentes con el uso de métodos anticonceptivos, pero la responsabilidad cae en el hombre del porte y uso del condón. En contraposición, está el grupo el grupo 3 (mujeres) el cual resiste a la opción del uso de métodos anticonceptivos, puesto que considera que los adolescentes no deben tener relaciones sexuales; sin embargo, el grupo 2 y el grupo 3 concuerdan que los medios comunicativos son estimulantes en el uso del preservativo, así mismo propulsores de las relaciones sexuales a temprana edad.

Tabla 6. Concepciones de padres sobre métodos anticonceptivos.

\begin{tabular}{|c|c|}
\hline Grupos & Descripciones \\
\hline Cinco & "El mejor método es no tener relaciones sexuales". \\
\hline Seis & $\begin{array}{l}\text { "Ios hijos deben portar y usar preservativos cuando vaya a tener, en el } \\
\text { futuro, una relación sexual y así evitar el embarazo". }\end{array}$ \\
\hline Siete & $\begin{array}{c}\text { Desde lo socio - cultural: "solo se utilizan en el matrimonio para no tener } \\
\text { muchos hijos" y "los adolescentes no al sexo, no anticonceptivos". } \\
\text { Desde lo religioso: el su uso de estos "está en contra de Dios". } \\
\text { Desde el sujeto: "es una forma de alcahuetear que las adolescentes } \\
\text { tengan sexo". } \\
\text { A nivel familiar: "toca que usen debemos apoyarlas porque a escondidas } \\
\text { puede ser peor". }\end{array}$ \\
\hline Ocho & $\begin{array}{l}\text { "No rotundo al uso de cualquier método de planificación" y "los hombres } \\
\text { adultos deben saber y utilizarlos". }\end{array}$ \\
\hline Nueve & Se reconoce la importancia, "las mujeres adolescentes deben emplearlos". \\
\hline
\end{tabular}

Fuente: elaboración propia

En la tabla 6, el grupo 9 presenta una visión liberal sobre los métodos de planificación, el cual concuerda con la concepción del grupo 4 frente al uso de estos métodos, de igual modo el grupo 8 es congruente con lo expuesto por sus hijas (grupo3). En cambio, los grupos 5 y 6 expresaron dos concepciones divergentes en cierta medida opuestas a la concepción de cada una sobre el acto sexual; es decir el grupo 5 consideró no tener sexo como método seguro a sabiendas de que los hombres adolescentes tienen sexo; y el grupo 6, recomendó el uso del condón aún en contra del acto sexual en adolescentes. Además, se identificó en los grupos 7 y 8 concepciones radicales (tradicionales y machistas) frente al no uso de métodos anticonceptivos en las adolescentes considerándolos insumos de adultos; su uso en jóvenes va en contra del pensamiento religioso y 
contribuye con el libertinaje. Sin embargo, en el grupo 7 hubo concepciones que estuvieron a favor de los métodos desde la obligatoriedad.

En este sentido, los datos de las subcategorías anteriores y de las descripciones de los grupos en su conjunto, como familia (padres o mamás o papás con sus respectivos hijos e hijas, se convierten en una unidad social) replican los significados tradicionales (imágenes de prototipos) asignados a la imagen de mujer y de hombre. Además, las descripciones se suscriben dentro de una cultura que "mira al sexo siempre con sospechas" el cual provoca la necesidad de trazar y mantener una frontera imaginaria entre la sexualidad buena y mala (Ruby s. f.) como lo indican las concepciones en cada una de las categorías.

Según Mitjans (2005), la feminidad y la masculinidad son constructos que surgen de los diversos sentidos (históricos, culturales, psíquicos, sociales y relacionales) de la sociedad que se emplea como agentes de referencia actualmente en la sociedad se mantiene para masculinidad ser caballero y para feminidad ser mujer juiciosa, los cuales pertenecen al siglo XVIII -, es decir, los patrones de comportamiento deben ser mantenidos tal cual como fueron instaurados. Desde el planteamiento de Nunes (2005), los resultados en cada una de las subcategorías responden a juicios condenatorios por parte de los padres o adultos porque los consideran contradictorios a las acciones morales tradicionales que debe realizar un caballero y una mujer juiciosa. Esto conlleva que toda pretensión sobre el acto sexual que este por fuera de la norma tradicional sea deslegitimizado, por tanto, se elimina el derecho a vivir su propia sexualidad, en especial en las mujeres adolescentes.

Los estereotipos también juegan un papel moldeador y condicionador; los y las adolescentes construyen sus representaciones mentales y sociales a partir de la repetición de esquemas familiares y sociales (el hombre es responsable de la mujer), como lo demuestran estos resultados y los de Bedoya (2014) sobre el paternalismo-protector, en los cuales se encontraron concepciones negativas hacia la "satisfacción personal" y la sobrevaloración de "pareja estable", que reflejan las expectativas ideales de la sociedad o familia.

Por ende, las acciones que ejerzan los adultos de forma directa (diálogos de poder y control) o indirecta (mediatización) conllevan a que los adolescentes expresen un reduccionismo ante la sexualidad. Ejemplo de ello, son los estereotipos sexuales (princesa y príncipe o la bella y la bestia, el vagabundo y la dama, etc.) que deben ser asumidos por los y las adolescentes dentro de roles sexistas ("solo las mujeres bonitas..." o "mujer juiciosa..." y "hombre ideal" u "hombre caballero"); concepciones transmitidas por las madres desde una visión tradicionalista (Jaramillo, Giraldo y Cardona, 2014).

Según los resultados, la hegemonía vertical provoca en ambos géneros de adolescentes concepciones de represión: por ejemplo, un patrón moralizador 
("solo cuando uno está casado", "no uso de métodos anticonceptivos", "hombre pecador u hombre espiritual”), aunque algunas concepciones frente a las subcategorías (métodos anticonceptivos, género y acto sexual), pueden revestirse de cierta reflexión, son de carácter informativo. Y un patrón preventivo, que se justifican en solo evitar: el embarazo, las enfermedades de transmisión sexual (ETS) o infecciones de transmisión sexual (ITS), inclusive lo que llaman relaciones tormentosas o que causen daño sexual (pérdida de la virginidad) y que no generen problemática familiar. Estas concepciones, desde la mirada Weeks (1998), no están alejadas de las restricciones a la autonomía sexual de la realidad social de la época victoriana.

Al respecto Torres, Amador y Rodríguez (2015), consideran que este paternalismo, en principio, arraiga la idea de romanticismo, para luego colocar en condiciones desigualitarias a la mujer con respecto al hombre; en tal escenario, se desconoce o se omiten las necesidades propias de la mujer (educativa, económica, ambiental, política, etc., también incluye el deseo, el placer y el sexo), como se evidencia en el uso de métodos anticonceptivos.

En concordancia con lo anterior, se evidencia la herencia generacional, especialmente en las madres hacia sus hijas, de la visión negativa adultocéntrica, en cuanto al desarrollo social de los adolescentes ("no son responsables" o "nada bueno puede esperarse de ellos”). También predomina la tendencia de animalismo (instinto-deseo) en el hombre (Olivarría, 2002), que en las descripciones encontradas responden a la clasificación o tipología de hombre y mujer adolescentes, pero que repercute en el desarrollo de identidad de los mismos, el cual Donas (2008), asegura que es una manera de estigmatizarlos. Las madres (al igual que el grupo de ambos padres) también generan expresiones adultocéntricas hacia sus hijos e hijas, que más que agredir, buscan ejercer poder y control sobre ellos y ellas. Sin embargo, Weeks (1998) indica que, son modos de propagar los esquemas de privilegio masculino.

Además, en la mayoría de casos, los textos escritos muestran el desacuerdo de los padres (en los tres grupos) sobre las relaciones sexuales, inclusive el noviazgo. Para los padres tanto las relaciones sexuales como el noviazgo (una conduce a la otra) son inadecuados, para ello sustentan y generalizan el argumento del animalismo imputado a los adolescentes-hombres, que según Fuller (2002), lo que pretende con dicha generalización es evitar la seducción o iniciación del acto sexual, en las adolescentes, incluso, en los adolescentes cuando animalizan a las adolescentes.

Se evidencia además en las descripciones, que las acciones (fuerzas) que ejercen los adultos de forma directa (diálogos de poder y control) o indirecta (mediatización) conllevan a que los adolescentes expresen un reduccionismo ante la sexualidad; ejemplo de ello son los estereotipos sexuales (princesa y 
príncipe o la bella y la bestia, el vagabundo y la dama, etc.) de la descripción de resultados, que deben ser asumidos por los y las adolescentes dentro de roles sexistas ("solo las mujeres bonitas..." o "mujer juiciosa..." y "hombre ideal" u "hombre caballero").

Las descripciones en las subcategoría tuvieron similitudes con lo expuesto por Berger, Jourdan y Collet (2006): los adolescentes están expuestos a la distorsión en los valores (más morales que éticos pues están arraigados a un credo), gracias la interacción directa del adolescente con su entorno (amigos, radio, tv, internet), ejercen en sí un efecto moldeador de gran alcance, alterando la imposición de valores por parte de la familia según el modelo de autoridad hegemónica vertical (Donas 2008). Esto es explicable desde Vaz, Vilar y Cardoso (1996), el desarrollo moral de los adolescentes se afecta cuando los modelos reales son inexistentes o débiles, por lo tanto, estos son remplazados por el modelo dominante de la sexualidad a la cual es sometido el o la adolescente.

Los datos muestran también que las relaciones entre padres (papás y mamás) se fundamentan sobre el pensamiento mítico, recurriendo al lenguaje para transmitir sus tradiciones; ejemplo de ello es la asignación de ciertos roles sociales a los sujetos: el adolescente se forma para ser dominante, fuerte, desinteresado, y la adolescente para ser sumisa y comedida (Nunes, 2005), que en las descripciones obtenidas hacen referencia sobre el papel de género en la sexualidad, transferido de padres a hijos o hijas, siendo más notorio en los diálogos sostenidos entre hijas adolescentes y mamás. Esto es comprensible puesto que socialmente (inclusive dentro del núcleo familiar) los esquemas de sexualidad son un producto de poder históricamente arraigado en nuestra cultura -en este contexto escolar es visible que los hombres definan y categoricen lo que es necesario y deseable para lo femenino-(Weeks 1998).

Otro ejemplo del control homogenizante, según las descripciones de este estudio y los resultados similares de Carvalho, et al. (2008), se presenta en los padres cuando resguardan sus concepciones sobre la sexualidad detrás de las ideas religiosas (anteponen a Dios o consideran pecado al acto sexual). Este pensamiento mítico (tradición cristiana) es para Durkheim, (1998), influyente sobre los valores morales y, por ende, sobre las conductas en el desarrollo de la sexualidad. Es decir, las normas culturales como las mismas creencias son extensibles y aplicadas a la sexualidad como mecanismo de control homogenizante del adolescente (Altmann y Martins 2009).

Es evidente que la familia es un núcleo social relevante para los y las adolescentes, pero desde los datos obtenidos, no se evidencia en ella un verdadero diálogo o construcción de saberes sobre la sexualidad, tan solo es transmitido (pareciese que el diálogo es acrítico y de "control" emitido y debe ser adoptado y aplicado). Montoya (2010), afirma que es la familia la promotora de los grandes 
vacíos en conocimientos sobre la sexualidad y la transmisión de conductas (Bonan, 2003). Por lo tanto, cuando el papel socializador de la familia disminuye en su impacto de autonomía en sus adolescentes, aseguran Fainsond (2010) y Montoya (2008), los padres recurren al discurso de riesgo y responsabilidad cuando los jóvenes asocian sexualidad con deseo y placer (Montoya, 2010), como los expresados, en especial, por el grupo 5 y grupo 6.

\section{Conclusiones}

Se identifica en ambos géneros la existencia de concepciones a favor y en contra de las prácticas sexuales. Pero estas concepciones son construidas desde experiencias culturales y sociales que no involucran la educación escolar o el conocimiento propio sobre la sexualidad como requisito para tomar decisiones (en términos de derechos humanos reproductivos) ante eventos de riesgo sexual.

Así mismo las concepciones expuestas responden, en su mayoría al conservacionismo el cual involucra el romanticismo y la benevolencia. En tiempos actuales, el conservacionismo ha construido la moderna ideología sexual, según Ruby (s. f.), la mujer es excluida de sus libertades sexuales y es sometida a través de atributos de virtud o pureza. Es decir, al hombre adolescente se le delega toda la responsabilidad de actuación y comportamiento en la práctica sexual (sujeto sexuado de derecho que debe ser consciente del respeto a la mujer y no proponer acto sexual) mientras que a la mujer adolescente se le considera sujeto por encima del hombre, el cual debe cuidar su imagen y honra (sujeto despojado de su propia sexualidad y derecho de decisión, el cual puede ser ejercida solo en el matrimonio).

Por ende las acciones que ejerzan los adultos de forma directa (diálogos de poder y control) o indirecta (mediatización) conllevan a que los adolescentes expresen un reduccionismo ante la sexualidad, ejemplo de ello son los estereotipos sexuales (princesa y príncipe o la bella y la bestia, el vagabundo y la dama, etc.) de la descripción de resultados, que deben ser asumidos por los y las adolescentes dentro de roles sexistas ("solo las mujeres bonitas..." o "mujer juiciosa..." y "hombre ideal" u "hombre caballero").

Las interpretaciones sobre las concepciones de la sexualidad en adolescentes y padres, afirman el planteamiento de Weeks (1998), donde éstas son parte de la construcción social de la sexualidad gracias a la influencia e intervención social; es así como los datos obtenidos entre las diferencias generacionales (en familias mono-nucleadas y bi-nucleadas), constatan la influencia social y generan concepciones moderadas en cambios de creencias (supuestas conductas en los psicodramas) entre algunos hijos e hijas y la mayoría de los padres (papás y mamás) que reflejan escalas de valores que atienden otras lógicas diferentes de 
actuar y pensar (referente situacional) del conservacionismo radical del siglo XX (Agudelo, 2004). Ejemplo de ello, es reconocer que las personas tienen relaciones sexuales prematrimoniales, la necesidad del uso de los métodos anticonceptivos y la adquisición de conocimiento en educación sexual, pero que no son prioridades en la formación de los adolescentes sino de los adultos.

Los padres que participaron en este estudio se encuentran en un proceso transitorio de cambios socio - culturales sobre el desarrollo sexual de sus hijos e hijas adolescentes, donde se acepta que los adolescentes inicien en el noviazgo (sin autorización de los padres) pero no aceptan la práctica sexual. Visto desde Durkheim (1998), responde a una evolución moral (los valores y decisiones de los sujetos de hoy distan a los sujetos de hace 30 años. Por ende, las negociaciones e interacciones van cambiando y constitucionalmente los adolescentes tiene derecho a la toma de decisiones) como requisito adaptativo a una sociedad local o a un contexto situacional propio (espacio y tiempo propio), pero que en Foucault (2007) puede explicarse como los cambios en el poder de la racionalidad (neoliberalismo) en donde las subjetividades de desobediencia son reguladas a partir de dispositivos de riesgo.

Cabe decir que el generar esta apertura social y cognitiva sobre el contenido de la sexualidad logró que los padres participaran directamente en la formación de sus hijos o hijas y compartieran de forma dialógica sus concepciones sobre la práctica sexual, mitigando el autoritarismo o dominación, el cual es necesario para la seguridad del desarrollo de la personalidad y social del adolescente siendo condición fundamental para la gobernanza (toma de decisiones y autonomía) del sujeto.

\section{Referencias}

Afanador, H. (2014). Particularidades en la formación de sexualidad en los y las adolescentes. Revista Cuadernos hispanoamericanos de psicología, 13(2), 91103.

Agudelo, G. (2004). Los valores morales en la juventud: su importancia y sus desafíos en Colombia. Revista de la facultad de Investigación de la ESAP, 53(2), 75-83.

Altmann, H. y Martins, C. (2009). Educação Sexual: ética, liberdade e autonomia. Critiba: Editora UFPR. 
Bedoya, C. L. (2014). Educación para la sexualidad y construcción de ciudadanía. Revista Sophia, $10(1)$, 95-106

Berger, D. Bernard, S. Khzami, S. Selmaoui, S. y De Carvalho, G. (2008). Sex education: teachers' and future teachers' conceptions and social representations; what relevance for teachers' training? XIII IOSTE Symposium, the Use of Science and Technology Education for Peace and Sustainable Development. Kuşadası. Turkey.

Berger, D. Jourdan, D. y Collet, R. (2006). An analysis of the representations of HIV/ AIDS in children from 9 to 11 in France: the effects of an educational programme. Science Education International. The official Journal of ICASE.

Bonder, G. (2008). La equidad de género en las políticas educativas: Una mirada reflexiva sobre premisas, experiencias y metas. Serie de trabajos monográficos, 2, 14-25. Argentina: Ediciones Sinergias. FLASCO.

Bonan, C. (2003). Derechos sexuales y reproductivos, reflexividad y transformaciones de la modernidad contemporánea. Brasil: documentos PRIGEPP.

Cárdenas, F. Contreras, A. y Navarro, B. (2011). La pre-escolarización del niño en la educación pública colombiana. Revista del instituto para la investigación educativa y el desarrollo pedagógico, 20, 79-98.

Carvalho, G. Bernard, S. Clement, P. y Berger, D. (2008). Health education: what influences teachers' and future teachers' conceptions from 16 countries of impel, imple and Middle East? XIII IOSTE Symposium, The use of Science and Technology Education for Peace and Sustainable Development. Kuşadası. Turkey.

Chen, P. (1976). The entity-relationship model: Toward a unified view of data. En: ACM Transactions on DataBase Systems.

Coad, P. y Yourdon, E. (1990). Object - Oriented Analysis. New Jersey: Yourdon Press.

Cole, M. (1984). La zona de desarrollo próximo: donde cultura y conocimiento se generan mutuamente. Revista Infancia y Aprendizaje, 25, 3- 17. 
Cornejo, I. (1992). El psicodrama aplicado al estudio de la recepción familiar televisiva. Revista Comunicación y Sociedad, 14(15), 39-63.

Cucatto, A. (2009). Un enfoque lingüístico-cognitivo para trabajar la conexión en los textos escritos. De la gramática al discurso. Revista Lationamericana de Estudios del Discurso, 9(1), 11-49.

Donas, B. (2002). Adolescencia y juventud Viejos y nuevos desafíos en los albores del nuevo milenio. En Donas Burak (Comp). Adolescencia y Juventud en América Latina (pp. 23-39). Cartago, Costa Rica: Editorial Tecnológica de Costa Rica.

Durkheim, E. (1998). Educación y Pedagogía. Ensayos y Controversia. Trad. Castaño, I. y Cataño, G. Buenos Aires: Editorial Losada S. A.

Foucault, (2007). La historia de la sexualidad. 1 la voluntad de saber. España: Siglo XXI editores S.A.

Fuller, (2002). Maternidad e identidad femenina: relato de sus desencuentros. En Donas Burak (Comp.). Adolescencia y Juventud en América Latina (pp. 225242). Costa Rica: Editorial Tecnológica de Costa Rica.

Heilborn, M. (1999). Sexualidade: o olhar das ciências sociais. Rio de Janeiro: Editora Zahar.

Jaramillo, O. Giraldo, P. y Cardona, R. (2014). Construcción de la feminidad en adolescentes de La Dorada, Caldas. Ánfora, 21(36), 165-185. Universidad Autónoma de Manizales.

Jiménez, J. (2011). La subjetividad del maestro en Colombia: la tensión entre la formación institucional y las prácticas institucionales $(1960$ - 2000). Revista del instituto para la investigación educativa y el desarrollo pedagógico, $20,47-58$.

Montoya, B. (2008). La historia no contada de una política despolitizada. Serie de trabajos monográficos, 2, 99-115. Argentina: Ediciones Sinergias. FLASCO.

Mitjans L. (2005). Sexualidad y adolescencia. Revista Pediatría de Atención Primaria 7, Suplemento. 1, 89-95. 
Musitu, G. (2000). Socialización familiar y valores en el adolescente: un análisis intercultural. Anuario de Psicología, 31, 15-32.

Musitu, G, y Cava, M. (2003). El rol del apoyo social en el ajuste de los adolescentes. Revista Intervención Psicosocial, 12 (2), 179-192.

Narodowski, M. (2011). Formar docentes en tiempos de equivalencias generalizadas. Revista del instituto para la investigación educativa y el desarrollo pedagógico, 20, 7-16.

Nunes, C. A. (2005). Desvendando a Sexualidade. Campinas: Papirus.

Olivarría, J. (2002). Hombres: identidad/es y sexualidad/es. III Encuentro de Estudios de Masculinidades. Santiago, Chile: FLACSO.

Ruby G. (s. f.). Reflexionando sobre el sexo: notas para una teoría radical de la sexualidad. Recuperado de: http://www.museo-etnografico.com/pdf/puntodefuga/150121 gaylerubin.pdf

Scott, J. (1996). El género: Una categoría útil para el análisis histórico. En Lamas Marta (Comp.). El género: la construcción cultural de la diferencia sexual (pp. 265-302). México: PUEG. Recuperado de http://www.inau.gub.uy/ biblioteca/scott.pdf

Silva, J. (2011). Sexualidade e Educação: um diálogo necesario. Revista Lugares de Educação, 1(2), $218-238$.

Torres, H., Amador, V. y Rodríguez, G. (2015). El descuido de sí misma en el proceso de Enamoramiento-Amor. Revista Electrónica Medicina, Salud y Sociedad, 5(2), 121-139.

Vaz, J. Vilar, D. y Cardoso, S. (1996). Educação sexual na escola. Lisboa: Universidade Aberta.

Weeks, J. (1998). Sexualidad. México D.F. Paidos, PUEG UNAM. 